\title{
Desenvolvimento de um Jogo Terapêutico para Prevenção da Recaída e Motivação para Mudança em Jovens Usuários de Drogas ${ }^{1}$
}

\author{
Anna Virginia Williams ${ }^{2}$ \\ Elisabeth Meyer \\ Flavio Pechansky \\ Universidade Federal do Rio Grande do Sul
}

\begin{abstract}
RESUMO - Apesar da alta prevalência do abuso, e dependência de drogas entre jovens, existe uma falta de intervenções originais desenvolvidas especificamente para o tratamento dessa população. Este estudo objetivou desenvolver uma técnica no formato de um jogo de cartas para ser utilizado no tratamento de jovens usuários de drogas. A técnica foi intitulada "Jogo da Escolha", e a sua elaboração envolveu: adaptação da linguagem, avaliação do conteúdo e elaboração de suas instruções junto aos profissionais de dependência química. Após um estudo-piloto, foram realizadas modificações nas instruções e no formato de aplicação, obtendose a versão atual do "Jogo da Escolha". O jogo demonstra ser útil para trabalhar crenças típicas de jovens usuários de drogas e promover estratégias de enfrentamento em situações de risco.
\end{abstract}

Palavras-chave: jogo terapêutico; crenças; estratégias de enfrentamento; jovens; uso de drogas.

\section{Development of a Therapeutic Game for Relapse Prevention and Motivation for Change in Young Drug Users}

\begin{abstract}
In spite of the high prevalence of drug abuse and dependence among youngsters, there is a lack of original interventions specifically developed for the treatment of this population. This study aimed at developing a technique in the format of a card game to be used in the treatment of young drug users. The technique was entitled: "Game of Choice" and its elaboration involved: adaptation of the language, evaluation of its content and elaboration of its instructions next to addiction specialists. After a pilot-study, modifications in the instructions and in the application format were made, and the present version of the "Game of the Choice" was obtained. The game demonstrates to be useful to approach typical core beliefs of young drug users and to promote coping skills in risk situations.
\end{abstract}

Key words: therapeutic game; beliefs; coping skills; youth; drug use.

A adolescência é uma faixa etária em que se registra uma grande preocupação em relação ao uso de drogas. Por diferentes fatores, os adolescentes encontram-se em uma fase de maior vulnerabilidade, sendo este momento da vida, um terreno fértil à experimentação o que poderá, ou não, levar ao início do abuso ou da dependência. O uso de drogas na adolescência é um dos problemas de saúde mental mais prevalentes. Segundo dados da Organização Mundial da Saúde (2002), é possível constatar que de 3,3 a 4,1\% da população mundial consome algum tipo de droga ilícita, sendo estimados em 2,5\% os usuários de maconha (World Health Organization, 2002).

Os pesquisadores e clínicos, em todo o mundo, têm grande interesse em utilizar todas as estratégias que possam aumentar as chances de sucesso dos programas de tratamento oferecidos para jovens usuários de drogas. É sabido que essa

1 Agradecimento aos colaboradores Maria Lúcia Tiellet Nunes, Alessandra Bianchi e à equipe do CDQUIM do Hospital Parque Belém e da Unidade de Dependência Química do Hospital Mãe de Deus.

2 Endereço: Centro de Pesquisa em Álcool e Drogas da UFRGS, Rua Ramiro Barcelos, 2350, sala 2201A - $2^{\circ}$ andar, Hospital de Clínicas de Porto Alegre, RS, Brasil 90035-903.E-mail: annaw06@gmail.com população facilmente se aborrece, apresenta uma urgência em ocupar-se com diferentes atividades, aderindo às mesmas por um curto espaço de tempo e, principalmente, comportase de acordo com a fantasia onipotente de que estão acima e a salvo de qualquer tipo de risco. Ainda que os artigos nacionais e internacionais reforcem a necessidade de abordagens desenvolvidas especificamente para os adolescentes, os modelos de intervenção utilizados foram desenvolvidos, em sua maioria, para o tratamento de adultos. Uma proposta de intervenção na qual o adolescente é tratado com técnicas especificas, focadas nas suas necessidades pessoais poderá ser especialmente relevante, podendo estimular alguns pacientes a permanecerem no tratamento por mais tempo.

Estudos recentes mostram que a terapia cognitivo-comportamental (TCC) é uma intervenção promissora e eficiente na redução do uso de drogas entre adolescentes (Dennis $\&$ cols., 2004). Caracteriza-se por utilizar uma estratégia lógica de tratamento, focada na modificação das cognições mal-adaptativas que aumentam o risco de recaída (Myers \& Brown, 1996). A TCC aplicada à dependência química procura trabalhar as cognições e comportamentos seqüenciais ao uso de drogas, tais como o manejo da "fissura", a evitação de situações de risco, a regulação do humor e da mudança do estilo de vida (Beck \& Bruce, 1998). Na terapia cognitiva da dependência química, os pensamentos e as crenças centrais 
são vistos como um importante mediador do uso de drogas, das emoções negativas e das respostas fisiológicas.

A Prevenção da Recaída (PR), desenvolvida por Marlatt e Gordon (1985), é uma abordagem amplamente utilizada nos tratamentos dos transtornos aditivos. Caracteriza-se por combinar o treinamento de habilidades comportamentais, intervenções cognitivas e mudanças no estilo de vida. Na PR, a recaída é considerada como parte do processo de mudança que, muitas vezes, pode ser vista como a forma pela qual o paciente recomeça o tratamento mais consciente do seu problema (Oliveira, Jaeger \& Schreiner, 2003). A recaída é considerada um processo no qual é possível identificar os seus antecedentes e, consequientemente, permite prevê-los e evitá-los. Dentro do modelo da PR, compreende-se que o retorno ao uso de drogas ocorre em situações de alto risco, nas quais há uma ameaça à abstinência. Nesses casos, o paciente não apresenta uma estratégia de enfrentamento para a situação de risco, o que baixa a sua sensação de auto-eficácia e aumenta a probabilidade de voltar aos níveis básicos do comportamento-alvo (Marlatt \& Gordon, 1985).

Também o modelo dos estágios de mudança (DiClemente \& Prochaska, 1982), que descreve como (processos) e quando (estágios) os indivíduos mudam sua conduta, permitiu uma melhor compreensão das freqüentes recaídas, bem como a oscilação da motivação dos pacientes para cessarem o consumo de drogas. Prochaska, DiClemente e Norcross (1992) descreveram os seguintes estágios de prontidão para mudança: Pré-contemplação (não estar consciente de ter um problema e não ter intenção de mudança), Contemplação (estar consciente que existe um problema, mas ainda não ter feito nada para mudar), Preparação (ter a intenção de realizar alguma mudança), Ação (concretizar a mudança) e Manutenção (já ocorreu a mudança e o paciente está procurando manter o comportamento modificado) (Prochaska \& cols., 1992). Entendendo cada estágio, é possível elaborar e aplicar intervenções adequadas ao nível de motivação do paciente.

O modelo dos Estágios de Mudança no uso de drogas apresenta implicações importantes tanto na mudança natural de um comportamento sobre o tempo, quanto no desenvolvimento das intervenções. O Modelo Transteórico postula que as intervenções necessitam focalizar nas diferentes variáveis para indivíduos em diferentes Estágios de Mudança. Por exemplo, aqueles nos estágios mais iniciais de mudança (Précontemplação) beneficiam-se mais da instrução e da compreensão das condutas de risco do que aqueles que já estão cientes dos riscos de seu comportamento e pretendem mudar logo (Preparação), ou que estão ativamente tentando mudar (Ação), beneficiando-se mais de intervenções baseadas no treinamento de habilidades e na auto-eficácia (Prochaska, Velicer, Fava, Rossi \& Tsoh, 2001; Stark \& cols., 1998).

Uma possibilidade de intervenção para adolescentes, como forma de tratar e prevenir problemas psicológicos e sociais, é o jogo terapêutico. A exemplo disso, o jogo psicoeducacional desenvolvido no Brasil - "ZIG-ZAIDS" - é um recurso lúdico para informação e prevenção da AIDS entre pré-adolescentes (Schall, Monteiro, Rebello \& Torres, 1999). Na área da dependência química, foi desenvolvido um CD-ROM para treinar habilidades de recusa a oferta de maconha (Duncan, Duncan, Beauchamp, Wells \& Ary, 2000).
Essa forma de abordar os problemas relacionados ao uso de drogas pode ser muito eficiente entre os jovens, em especial pelo seu apelo atrativo e dinâmico que pode vir a aumentar a adesão ao tratamento. A escassez de técnicas específicas para jovens usuários de drogas constitui um grande obstáculo para o tratamento dessa população (Kaminer, Burleson \& Goldberger, 2002; Hser \& cols., 2001). É importante salientar que a maioria das técnicas aplicadas aos adolescentes (Burleson \& Kaminer, 2005) consistem em simples transposições de técnicas aplicadas a amostras adultas. Com isto queremos dizer que existe uma necessidade emergencial de desenvolver e aperfeiçoar tratamentos focados na população jovem, a curto e a longo prazo.

Pelo exposto, o presente artigo pretende apresentar o processo de desenvolvimento de um jogo terapêutico destinado a jovens usuários de drogas. Essa técnica objetiva abordar crenças típicas a respeito do uso de drogas e promover habilidades de enfrentamento para situações que ameacem a abstinência do paciente, visando motivá-lo para a mudança e prevenir a recaída. Este estudo foi aprovado pelo comitê de ética do Hospital de Clínicas de Porto Alegre $\left(n^{\circ}\right.$ do protocolo 04-175)

\section{Objetivo do jogo}

A técnica proposta compõe-se de um jogo de cartas denominado "Jogo da Escolha" para ser utilizado dentro de um contexto terapêutico, com pacientes usuários de drogas. $\mathrm{O}$ objetivo do jogo é abordar crenças típicas de jovens usuários de drogas, bem como desenvolver e ensinar habilidades de manejo de situações de risco. Também, são trabalhadas, na técnica, situações relacionadas à pressão do grupo, elementos que acionam o comportamento relacionado ao uso de drogas e pensamentos mantenedores do uso de drogas. O jogo estimula o paciente a pensar em novas possibilidades de agir e em formas diferentes de refletir quando estiver frente a uma situação que lhe ative o comportamento do uso de drogas. Esta intervenção possibilita o aprendizado de que, para cada crença facilitadora ou ativadora do comportamento maladaptativo de uso de drogas, há no mínimo uma estratégia possível para enfrentar aquela situação e evitar o uso.

Durante o jogo, o terapeuta estimula o questionamento de crenças comuns que usuários de drogas costumam cultivar, como, por exemplo: "não vale a pena largar as drogas porque me sinto um fracasso quando recaio". Dessa forma, o paciente pode ponderar a respeito do seu problema, e reestruturar crenças mal-adaptativas como, por exemplo, "posso ficar sem usar drogas com o auxílio de alguma pessoa". Ao trabalhar técnicas de resolução de problemas, o paciente poderá melhorar o seu repertório de habilidades de enfrentamento e, conseqüentemente, a sua auto-eficácia. Sentindo-se mais capaz de lidar com situações de risco, a motivação para mudar o comportamento em relação às drogas pode aumentar, auxiliando o paciente a efetivamente parar ou a diminuir o seu uso.

\section{Método}

O desenvolvimento da técnica ocorreu em quatro fases distintas. Primeiramente, foi feita a elaboração das frases 
que foram colocadas em cartas, seguida da adaptação da linguagem, conteúdo e instruções, junto aos pacientes e posteriormente com especialista. Por último, foi realizada a avaliação do conteúdo e ordenamento das cartas.

\section{Primeira fase: criação da técnica}

A primeira fase de elaboração da técnica ocorreu em 1999 no Centro de Pesquisa em Álcool e Drogas (CPAD) da Universidade Federal do Rio Grande do Sul (UFRGS), por meio da coleta dos pensamentos típicos de jovens que apresentavam problemas com drogas. Duas residentes em Psiquiatria realizaram um levantamento, na literatura, de crenças centrais de jovens usuários de drogas e das estratégias de enfrentamento para situações de risco de recaída. Posteriormente, foram realizados três grupos distintos com meninos em situação de rua com problemas com drogas. Estes encontros permitiram verificar a validade dessas crenças e das estratégias por eles utilizadas, assim como elaborar uma lista dos temas mais freqüentemente abordados pelos sujeitos. Esses temas foram apresentados sob forma de assertivas, designadas como positivas ou negativas.

As assertivas positivas refletem os pensamentos e as ações utilizadas na tentativa de resistir ao uso de drogas, como por exemplo, "Quando me dou conta do que me faz. usar drogas tenho menos chance de recair". As assertivas negativas ilustram crenças que facilitam e mantém o uso de drogas, como por exemplo: "As drogas me fazem esquecer os meus problemas".

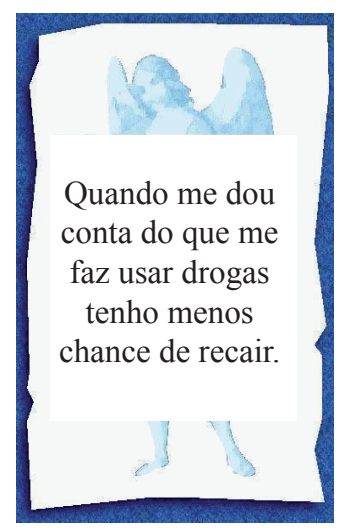

(1)



(2)
Figura 1. Exemplo de cartas com assertivas negativas (2) e positivas (1).
De posse dessas assertivas, foram elaborados dois baralhos de cartas. As assertivas positivas foram descritas em cartas de cor azul, com a representação de um anjo ao fundo, e as assertivas negativas foram confeccionadas em cartas de cor vermelha, com a reprodução de um diabo ao fundo, conforme ilustra a Figura 1. A produção de uma dicotomia entre os dois baralhos, um positivo e um negativo, procurou refletir a ambivalência do paciente em relação à droga.

Adicionalmente foi desenvolvida uma sugestão de instrução para o jogo, quando se constituiu essa a primeira versão. Parte desse jogo foi submetida à apreciação da comunidade científica em um evento internacional (Pechansky, 1999).

\section{Segunda fase: refinamento da técnica}

Com o objetivo de avaliar a adequação das assertivas e as instruções, foram realizados, em 2005, quatro grupos focais com três voluntários em cada, totalizando 12 sujeitos. Participaram 11 homens e uma mulher (média de idade 18 anos, $D P=1,8$ ). Os participantes eram pacientes ambulatoriais de um centro de tratamento de dependência química de Porto Alegre. Os grupos foram coordenados por uma terapeuta com mais de 20 anos de experiência e observados pela primeira autora deste artigo. Os grupos tinham duração de uma hora e todas as sessões foram gravadas e transcritas.

Nos grupos focais, os jovens eram expostos às cartas originais, desenvolvidas na primeira fase, uma de cada vez. A terapeuta perguntava se os participantes haviam compreendido as frases e se teriam alguma sugestão para torná-las mais compreensíveis. Também lhes era questionada a veracidade das cartas, ou seja, se aqueles pensamentos já lhes haviam ocorrido. Todas as cartas originais foram apresentadas para, no mínimo, três grupos.

As sugestões provenientes dos grupos focais foram apresentadas a um grupo de profissionais do CPAD com o objetivo de escolher a assertiva mais simples e compreensível, sendo mantida a idéia original da carta. Foi consenso não utilizar frases extensas e o uso de gírias. O grupo foi constituído por três psiquiatras e uma terapeuta ocupacional, tendo duração de uma hora e meia. Essa etapa permitiu a elaboração de cartas cuja linguagem fosse compreensível para jovens usuários de drogas com baixa escolaridade. Desta forma, as cartas poderiam ser compreendidas por um número maior de pessoas, possibilitando a sua aplicação em diversos contextos terapêuticos. O Quadro 1 ilustra os procedimentos dessa etapa. Paralelamente, optou-se pela retirada de algumas cartas e outras foram acrescentadas.

Quadro 1. Exemplo do procedimento de obtenção da versão final das cartas.

\begin{tabular}{|c|c|c|c|c|c|}
\hline Carta Original & Sugestão do grupo 1 & Sugestão do grupo 2 & Sugestão do grupo 3 & Tomada de decisão & Carta final \\
\hline $\begin{array}{l}\text { Quando me dou } \\
\text { conta do que causa } \\
\text { minhas fissuras, } \\
\text { não sou pego de } \\
\text { surpresa: tenho } \\
\text { menos chance de } \\
\text { recair. }\end{array}$ & $\begin{array}{l}\text { Quando me dou conta } \\
\text { do que me faz usar } \\
\text { drogas não sou pego } \\
\text { de surpresa e tenho } \\
\text { menos chance de } \\
\text { voltar a usar. }\end{array}$ & $\begin{array}{l}\text { Quando eu caio na real do } \\
\text { que me dá vontade de usar } \\
\text { não sou pego distraído e } \\
\text { tenho menos possibilidade } \\
\text { de voltar a usar. }\end{array}$ & $\begin{array}{l}\text { Quando eu sei o que } \\
\text { me tenta tenho mais } \\
\text { chance de recair. }\end{array}$ & $\begin{array}{l}\text { Grupo com } \\
\text { profissionais da } \\
\text { CPAD. }\end{array}$ & $\begin{array}{l}\text { Quando me dou } \\
\text { conta do que me faz } \\
\text { usar drogas tenho } \\
\text { menos chance de } \\
\text { recair. }\end{array}$ \\
\hline
\end{tabular}




\section{Terceira fase: avaliação do conteúdo}

Com o objetivo de confirmar se o jogo estava "tratando aquilo a que ele se propunha a tratar", foi organizado um grupo focal com psiquiatras, psicólogos e consultores em dependência química de uma unidade de internação para dependência química de Porto Alegre. O grupo era composto por oito profissionais e teve duração de 40 minutos.

Para cada assertiva apresentada, os participantes reportavam, livremente, as habilidades que acreditavam poderem ser trabalhadas com o paciente. As habilidades que predominaram no grupo foram as seguintes:

- $\quad$ resolução de problemas e tomada de decisão;

- desenvolvimento de estratégias de enfrentamento;

- aumento da auto-eficácia;

- aumento da auto-estima;

- $\quad$ aumento da tolerância à frustração;

- reflexão a respeito da auto-imagem;

- reflexão sobre as vantagens e desvantagens relacionadas ao uso de drogas;

- $\quad$ reflexão sobre a sensação de controle sobre o uso de drogas;

- diminuição de pensamentos dicotomizados;

- questionamento de crenças e pensamentos automáticos sobre o uso de drogas;

- aumento do auto-monitoramento;

- $\quad$ identificação de estratégias de enfrentamento;

- manejo da pressão social e desenvolvimento da capacidade de recusa para a oferta de droga;

- manejo da fissura;

- controle da impulsividade;

- $\quad$ aquisição da responsabilidade pelo seu problema.

De uma forma geral, pode-se dizer que as habilidades citadas pelos profissionais se enquadram no modelo da Prevenção de Recaída (Marlatt \& Gordon, 1985) e do modelo cognitivo para dependência química (Beck \& Bruce, 1998; Beck, Wright, Newman \& Liese, 1993), o que demonstra que a técnica desenvolvida estava coerente com a base teórica proposta.

\section{Quarta fase: determinação da ordem das cartas}

Para desenvolver uma sequiência de apresentação das cartas foram consultados, individualmente, dois psiquiatras e uma psicóloga que ainda não haviam tido contato com a intervenção. As cartas positivas foram organizadas por agrupamento de estratégias similares, como apresentado no Quadro 2.

A ordem das cartas negativas foi baseada na lógica referente a "dar-se conta do seu problema", ou seja, as primeiras cartas, de 1 a 7, apresentam pensamentos que sugerem pouca consciência sobre o problema com drogas, como por exemplo, "existem situações que têm tudo a ver com drogas: festas e shows...". Esse seria o pensamento de um indivíduo pré-contemplador, o qual não considera o uso de drogas um problema. As últimas cartas negativas, de 8 a 14, expressam crenças disfuncionais, mas com maior consciência a respeito do problema, como por exemplo, "não vale a pena largar as
Quadro 2. Habilidades referentes a carta positiva.

\begin{tabular}{|c|c|}
\hline Habilidade & Cartas \\
\hline \multirow{2}{*}{$\begin{array}{l}\text { Expectativas } \\
\text { positivas em relação } \\
\text { à abstinência }\end{array}$} & $\begin{array}{l}\text { 1. Estou aprendendo a enfrentar os meus } \\
\text { problemas de cara limpa! }\end{array}$ \\
\hline & $\begin{array}{l}\text { 2. Depois que eu parei de usar drogas algumas } \\
\text { coisas na minha vida mudaram para melhor! }\end{array}$ \\
\hline \multirow{2}{*}{$\begin{array}{l}\text { Re-significação } \\
\text { de pensamentos } \\
\text { dicotômicos }\end{array}$} & $\begin{array}{l}\text { 3. Agora estou podendo ver que nem sempre as } \\
\text { coisas são tudo ou nada. }\end{array}$ \\
\hline & $\begin{array}{l}\text { 4. Não sou tão ruim assim... tenho meus pontos } \\
\text { positivos. }\end{array}$ \\
\hline \multirow{2}{*}{ Auto-monitoramento } & $\begin{array}{l}\text { 5. Quando me dou conta do que me faz usar } \\
\text { drogas tenho menos chance de recair. }\end{array}$ \\
\hline & $\begin{array}{l}\text { 6. Quando eu consigo pensar antes, me saio } \\
\text { melhor }\end{array}$ \\
\hline \multirow{2}{*}{$\begin{array}{l}\text { Habilidade de recusa } \\
\text { e antecipação das } \\
\text { consequiências }\end{array}$} & $\begin{array}{l}\text { 7. Quando eu sinto que não conseguirei dizer } \\
\text { não, decido não sair com meus amigos. }\end{array}$ \\
\hline & $\begin{array}{l}\text { 8. Quando me lembro de como me sinto mal } \\
\text { depois que uso drogas me dou conta que não } \\
\text { vale a pena. }\end{array}$ \\
\hline \multirow{2}{*}{ Busca de auxílio } & $\begin{array}{l}\text { 9. Posso planejar evitar o uso de drogas com a } \\
\text { ajuda do meu terapeuta. }\end{array}$ \\
\hline & $\begin{array}{l}\text { 10. Posso ficar sem usar drogas com o auxílio } \\
\text { de alguma pessoa. }\end{array}$ \\
\hline \multirow{2}{*}{$\begin{array}{l}\text { Reflexão sobre a } \\
\text { sensação de controle } \\
\text { do uso de drogas }\end{array}$} & $\begin{array}{l}\text { 11. Sei que ainda posso me esforçar para tentar } \\
\text { parar de usar drogas. }\end{array}$ \\
\hline & $\begin{array}{l}\text { 12. Me dei conta que não é tão fácil controlar } \\
\text { meu uso de drogas. }\end{array}$ \\
\hline \multirow{2}{*}{$\begin{array}{l}\text { Cartas } \\
\text { individualizadas (o } \\
\text { paciente é solicitado } \\
\text { a completar a frase) }\end{array}$} & $\begin{array}{l}\text { 13. Já tive vontade, mas consegui não usar } \\
\text { drogas quando... (complete) }\end{array}$ \\
\hline & $\begin{array}{l}\text { 14. Acho que pensar sobre o meu uso de drogas } \\
\text { está me ajudando a... (complete) }\end{array}$ \\
\hline
\end{tabular}

drogas porque me sinto um fracasso quando recaio". Esse pensamento ilustra um sujeito em contemplação, ambivalente em relação a parar ou não o uso de drogas. Assim, os pacientes no estágio de mudança inicial, pré-contemplação, irão identificar-se com as primeiras cartas, e pacientes, em estágios mais adiantados, contemplação e ação, irão identificar-se com as últimas cartas. Ao utilizar essa seqüência, a técnica não se torna confrontativa para o paciente, mesmo quando ele se encontra em estágios de mudança mais iniciais.

\section{Resultados}

\section{Apresentação da técnica na sua forma atual}

O "Jogo da Escolha", em seu formato atual, é composto por um baralho de 28 cartas: 14 cartas positivas e 14 cartas negativas.

As cartas positivas apresentam frases que protegem o paciente do uso de drogas, por reforçarem vantagens relativas à abstinência. Algumas cartas positivas solicitam que o participante complete frases como, por exemplo: "já tive vontade, mas consegui não usar drogas quando... (complete)", possibilitando que o paciente possa pensar a respeito da sua própria experiência durante o jogo. As cartas positivas pretendem desenvolver habilidades como: 1) enfrentamento de situações de risco, 2) aumento da auto-eficácia, 3) reflexão sobre o controle em relação ao uso, 4) re-significação de pensamentos dicotômicos ("tudo ou nada"), e 5) aumento 
do automonitoramento e da capacidade de antecipar as conseqüências negativas do uso de drogas.

As cartas negativas evidenciam pensamentos comuns aos usuários de drogas, tais como: justificativas sociais do uso de drogas ("a única forma de eu me enturmar é usando drogas"), questões relacionadas a automedicação através do uso de drogas ("as drogas me fazem eu esquecer os meus problemas"), e fissura ("muitas vezes a droga é mais forte que eu"). Essas condutas vão desde a negação do problema, colocando a responsabilidade em questões externas, até a percepção de que a droga ocupa uma função similar à automedicação ou à socialização. As últimas cartas também trazem questões relacionadas à fissura e as expectativas negativas em relação à abstinência. As cartas negativas e positivas se encontram no Quadro 3:

Quadro 3. Cartas positivas e negativas.

\begin{tabular}{|c|c|c|}
\hline Número & Cartas Positivas & Cartas Negativas \\
\hline 1 & $\begin{array}{l}\text { Estou aprendendo a enfrentar } \\
\text { os meus problemas de cara } \\
\text { limpa! }\end{array}$ & $\begin{array}{l}\text { Existem situações que tem } \\
\text { tudo a ver com drogas: } \\
\text { festas, shows... }\end{array}$ \\
\hline 2 & $\begin{array}{l}\text { Depois que eu parei de usar } \\
\text { drogas algumas coisas na } \\
\text { minha vida mudaram para } \\
\text { melhor! }\end{array}$ & $\begin{array}{l}\text { Quando eu uso drogas me } \\
\text { sinto bem! }\end{array}$ \\
\hline 3 & $\begin{array}{l}\text { Agora estou podendo ver que } \\
\text { nem sempre as coisas são tudo } \\
\text { ou nada. }\end{array}$ & $\begin{array}{l}\text { Eu paro na hora que quiser, } \\
\text { só que ainda não estou com } \\
\text { vontade. }\end{array}$ \\
\hline 4 & $\begin{array}{l}\text { Não sou tão ruim assim... } \\
\text { tenho meus pontos positivos. }\end{array}$ & $\begin{array}{l}\text { Eu fico muito chato quando } \\
\text { estou de cara. }\end{array}$ \\
\hline 5 & $\begin{array}{l}\text { Quando me dou conta do } \\
\text { que me faz usar drogas tenho } \\
\text { menos chance de recair. }\end{array}$ & $\begin{array}{l}\text { A única forma de eu me } \\
\text { enturmar é usando drogas. }\end{array}$ \\
\hline 6 & $\begin{array}{l}\text { Quando eu consigo pensar } \\
\text { antes, me saio melhor! }\end{array}$ & $\begin{array}{l}\text { As drogas fazem eu esquecer } \\
\text { os meus problemas. }\end{array}$ \\
\hline 7 & $\begin{array}{l}\text { Quando eu sinto que não } \\
\text { conseguirei dizer não, decido } \\
\text { não sair com meus amigos. }\end{array}$ & $\begin{array}{l}\text { Quando estou triste, nervoso, } \\
\text { ou sozinho, as drogas me } \\
\text { fazem sentir melhor. }\end{array}$ \\
\hline 8 & $\begin{array}{l}\text { Quando me lembro de como } \\
\text { me sinto mal depois que uso } \\
\text { drogas me dou conta que não } \\
\text { vale a pena. }\end{array}$ & $\begin{array}{l}\text { Quando meus amigos me } \\
\text { oferecem, não consigo dizer } \\
\text { não. }\end{array}$ \\
\hline 9 & $\begin{array}{l}\text { Posso planejar evitar o uso de } \\
\text { drogas com a ajuda do meu } \\
\text { terapeuta. }\end{array}$ & $\begin{array}{l}\text { Eu não sei o que acontece: } \\
\text { quando eu me dou conta, } \\
\text { estou usando drogas de } \\
\text { novo! }\end{array}$ \\
\hline 10 & $\begin{array}{l}\text { Posso ficar sem usar drogas } \\
\text { com o auxílio de alguma } \\
\text { pessoa. }\end{array}$ & $\begin{array}{l}\text { Não é que eu queira usar } \\
\text { drogas é que a fissura é } \\
\text { muito forte... }\end{array}$ \\
\hline 11 & $\begin{array}{l}\text { Sei que ainda posso me } \\
\text { esforçar para tentar parar de } \\
\text { usar drogas. }\end{array}$ & $\begin{array}{l}\text { Muitas vezes a droga é mais } \\
\text { forte que eu. }\end{array}$ \\
\hline 12 & $\begin{array}{l}\text { Me dei conta que não é tão } \\
\text { fácil controlar meu uso de } \\
\text { drogas. }\end{array}$ & $\begin{array}{l}\text { Se eu largar as drogas eu } \\
\text { vou ficar com fissura e meu } \\
\text { corpo vai sentir falta. }\end{array}$ \\
\hline 13 & $\begin{array}{l}\text { Já tive vontade, mas consegui } \\
\text { não usar drogas quando... } \\
\text { (complete) }\end{array}$ & $\begin{array}{l}\text { Não vale a pena largar as } \\
\text { drogas porque me sinto um } \\
\text { fracasso quando recaio. }\end{array}$ \\
\hline 14 & $\begin{array}{l}\text { Acho que pensar sobre o } \\
\text { meu uso de drogas está me } \\
\text { ajudando a... (complete) }\end{array}$ & $\begin{array}{l}\text { Agora não adianta parar: eu } \\
\text { já me detonei com as drogas. }\end{array}$ \\
\hline
\end{tabular}

\section{Instruções da técnica}

Para testar a mecânica proposta para a intervenção, foi realizado um estudo-piloto com 20 pacientes ambulatoriais do mesmo centro de tratamento onde ocorreram os grupos focais da fase 2. A média de idade dos sujeitos foi de 19,1 anos $(D P=1)$, e o grupo compunha-se de 16 homens e de quatro mulheres. Metade desses pacientes foi exposta à técnica experimental e metade foi exposta a um jogo controle intitulado "O jogo da vida" . A aplicação foi feita em grupos com três ou quatro sujeitos e os jovens eram designados randomicamente para cada grupo. Os grupos foram coordenados por uma psiquiatra e uma terapeuta ocupacional com mais de 10 anos de experiência em saúde mental, tendo duração de 45 minutos. Foram aplicadas duas escalas: SOCRATES (Miller, 1995) para avaliar as mudanças na motivação para cessar o consumo de drogas, e Balança Decisional (Velicer, DiClemente, Prochaska \& Brandenburg, 1985) com o objetivo de avaliar possíveis modificações na percepção das vantagens e desvantagens em relação ao uso de drogas. As escalas eram aplicadas por estudantes de Medicina e de Psicologia antes e imediatamente após a realização dos grupos.

Os resultados desse estudo-piloto indicaram não haver mudança intragrupos, pré $v s$. pós grupo, e nem entre grupos, controle $v s$. experimental. Esses dados permitiram concluir que, para haver algum efeito em uma doença grave e crônica, como a dependência química, seria necessário aumentar a "dose" da intervenção e diminuir a variabilidade do estudo. Com isto queremos dizer que, durante uma única sessão nem todas as cartas eram apresentadas, em função do tempo, e nem todos os sujeitos do grupo participavam. Dessa forma, desenvolveu-se uma nova intervenção constituída por três sessões individuais de 45 minutos cada, em que todas as cartas eram apresentadas pelo menos uma vez. As instruções da intervenção foram elaboradas por quatro terapeutas familiarizados com o jogo. Essa fase do estudo foi submetida à apreciação da comunidade científica em eventos nacionais e internacional (Williams \& Pechansky, 2004a; Williams \& Pechansky, 2004b; Williams \& Pechansky, 2004c) e o feedback positivo dessa comunidade reforçou a importância de desenvolver uma técnica para jovens usuários de drogas que fosse, ao mesmo tempo, lúdica e terapêutica.

Na sua versão atual, o jogo é executado da seguinte forma: durante a primeira sessão, as cartas negativas são apresentadas uma de cada vez, de acordo com a sequiência elaborada no estudo. O paciente é convidado a refletir a respeito das assertivas, uma a uma, sendo questionado se aquele pensamento já lhe ocorreu e o que ele pensa a respeito daquela situação. Após responder, o paciente tenta buscar uma estratégia de enfrentamento dentro do leque de opções oferecido nas cartas positivas para solucionar aquela situação. Assim, o paciente forma pares de cartas negativas (crenças disfuncionais) com cartas positivas (estratégias de enfrentamento). Um exemplo de combinação seria, para a carta negativa "as

3 O jogo da vida ®, Estrela - é um jogo de tabuleiro jogado em grupo, a partir de 8 anos de idade; os jogadores percorrem um caminho em que têm de lidar com situações comuns do ciclo da vida, formar-se, casar, ter filhos, lidar com dinheiro, ganhos e perdas. 
drogas fazem eu esquecer os meus problemas", o paciente escolher a carta positiva "quando me lembro de como me sinto mal depois que uso drogas, me dou conta que não vale a pena". A combinação entre cartas negativas e positivas não é fixada pelo terapeuta, ficando a critério do paciente escolher as respostas de enfrentamento que lhe parecem apropriadas. O benefício dessa flexibilidade está na possibilidade de o terapeuta examinar criticamente com o paciente o tipo de escolha realizada, bem como outras opções.

A quantidade de cartas positivas e negativas utilizadas varia de acordo com a sessão. A primeira sessão é iniciada apresentando as sete primeiras cartas negativas, e no fim do jogo, o terapeuta oferece sete cartas positivas, aleatoriamente, para o paciente formar pares com as situações nas cartas negativas. Na segunda sessão, são apresentadas as cartas negativas, de 8 a 14, e são oferecidas todas as cartas positivas para o paciente formar as combinações. Na terceira sessão, são apresentadas todas as cartas negativas, de 1 a 14, e é solicitado ao paciente que escolha as cartas com cujas assertivas ele mais se identifique ou sobre as quais ele pense mais. As assertivas escolhidas pelo paciente são exploradas uma a uma pelo terapeuta, que irá oferecer todas as cartas positivas para a solução das situações. Adicionalmente, na terceira sessão é oferecida a possibilidade de o paciente escrever as suas próprias cartas positivas, pensando em estratégias de enfrentamento específicas para o seu caso. Ao final da sessão, o paciente leva as cartas que ele mesmo criou e poderá utilizá-las como cartões-lembrete.

Recomenda-se que o aplicador da técnica seja um profissional da área da Saúde, que trabalhe com dependência química, com algum treino em terapia cognitiva comportamental e prevenção de recaída. Espera-se que o aplicador assuma uma postura motivacional, apoiando-se nas técnicas da Entrevista Motivacional fundamentadas na teoria de Miller, principalmente no que compete a evitar confrontação, desenvolver discrepância, fluir com a resistência, estimular a auto-eficácia e a expressar empatia frente ao paciente (Miller \& Rollnick, 1991).

\section{Discussão dos Resultados}

Este artigo teve como objetivo descrever o desenvolvimento e a base teórica utilizada na confecção de um jogo de cartas para adolescentes usuários de drogas. A meta foi apresentar a metodologia empregada nas diferentes fases necessárias para a estruturação de uma nova técnica que pretende ser somada ao atual leque de abordagens utilizadas para auxiliar os pacientes a cessarem o uso de drogas.

O desenvolvimento de um jogo terapêutico baseando-se em modelos teóricos já consagrados de tratamento, somado a uma metodologia científica rigorosa, permitiu a elaboração de uma técnica que parece ser dinâmica e atrativa para a população jovem. O processo de desenvolver um jogo de cartas que permita aumentar as chances de mudar o comportamento de uso de drogas por adolescentes abrange muitos elementos e exige uma metodologia cuidadosa. Durante todo o curso de desenvolvimento do jogo, buscou-se empregar uma linguagem que correspondesse ao máximo à utilizada por adolescentes usuários de drogas de todos os estratos socioeconômicos e culturais. A determinação da sequiência de apresentação das cartas para o paciente seguiu uma ordem motivacional baseada nos Estágios de Mudança e oportunizou o desenvolvimento de uma atmosfera não-confrontadora, ideal para se trabalhar com adolescentes usuários de drogas. Também a avaliação do conteúdo foi eficiente em confirmar que a técnica estava calcada em uma base teórica apropriada. Nutre-se a expectativa de que essa técnica possa ser utilizada para os devidos fins terapêuticos, como em ambulatórios, internações psiquiátricas e postos de saúde, podendo ser adaptada futuramente para um formato de grupo.

A realização do estudo-piloto propiciou fazerem-se as necessárias adequações no nível de compreensão da maioria dos jovens. Além disso, foi possível observar que o jogo seria mais eficiente se empregado em três sessões individuais. A técnica, no seu formato atual, permite que o paciente trabalhe situações comuns a outros pacientes usuários de drogas nas cartas, bem como situações específicas do seu contexto de vida, em especial, na terceira sessão, quando o paciente escolhe as cartas com as quais se identifica e pode escrever cartas positivas que lhes sejam adequadas e úteis. Estudos futuros são necessários para identificar a eficácia do jogo, a curto e a longo prazo, além de investigar quais os pacientes que se beneficiarão desta técnica. Um ensaio clínico poderia examinar se a diminuição do uso de drogas é devida à técnica utilizada como parte do tratamento ou se aconteceria naturalmente. Isso produziria dados a partir dos quais se poderiam identificar os efeitos da intervenção específicos. Estudos adicionais deverão ser desenhados considerando uma amostra representativa de jovens usuários de drogas, incluindo meninos e meninas, de diferentes níveis socioeconômicos e educacionais. Os dados daí coligidos poderão fornecer uma visão mais clara do efeito do jogo no processo de mudança do comportamento aditivo nessa população. Adolescentes já estão tentando parar com o uso de drogas ou que estão abstinentes poderão responder diferentemente daqueles que ainda não estão considerando mudar esse comportamento (Pré-contemplação).

Frente aos dados epidemiológicos, faz-se importante salientar que adolescentes usuários de drogas, quando não tratados, provavelmente, continuam a fazer uso delas quando adulto - esse fato deve servir de motivação e de incentivo para que estudos, como o apresentado neste artigo e os já sugeridos, sejam apoiados e executados.

\section{Referências}

Beck, J. S. \& Bruce, S. L. (1998). Cognitive Therapy. Em R. J. Frances \& S. I. Miller (Orgs.), Clinical Textbook of Addictive Disorders ( $2^{\mathrm{a}}$ ed., pp. 547-573). New York: The Guilford Press.

Beck, A. T., Wright, F. D., Newman C. F. \& Liese B. S. (1993). Cognitive Therapy of Substance Abuse. New York: Guilford Publications.

Burleson, J. A. \& Kaminer, Y. (2005). Self-efficacy as a predictor of treatment outcome in adolescent substance use disorders. Addictive Behaviour, 30, 1751-1764.

Dennis, M., Godley, S. H., Diamond, G., Tims, F. M., Babor, T., Donaldson, J., Liddle, H., Titus, J. C., Kaminer, Y., Webb, C., Hamilton, N. \& Funk, R. (2004). The Cannabis Youth Treatment (CYT) Study: main findings from two randomized trials. Journal of Substance Abuse Treatment, 27, 197-213. 
DiClemente, C. C. \& Prochaska, J. O. (1982). Self-change and therapy change of smoking behavior: a comparison of processes of change in cessation and maintenance. Addictive Behaviour, 7, 133-142.

Duncan, T. E., Duncan, S. C., Beauchamp, N., Wells, J. \& Ary, D. V. (2000). Development and evaluation of an interactive CD-ROM refusal skills program to prevent youth substance use: "refuse to use". Journal of Behavioral Medicine, 23, 59-72.

Hser, Y. I., Grella, C. E., Hubbard, R. L., Hsieh, S. C., Fletcher, B. W., Brown, B. S. \& Anglin, M. D. (2001). An evaluation of drug treatments for adolescents in 4 US cities. Archives of General Psychiatry, 58, 689-695.

Kaminer, Y., Burleson, J. A. \& Goldberger, R. (2002). Cognitivebehavioral coping skills and psychoeducation therapies for adolescent substance abuse. The Journal of Nervous and Mental Disease, 190, 737-745.

Marlatt, G. A. \& Gordon, J. R. (1985). Relapse Prevention: Maintenance strategies in the treatment of addictive behaviors. New York: Guilford Press.

Miller, W. R. (1995). SOCRATES The Stages of Change Readiness and Treatment Eagerness Scale (Version 8). Albuquerque: University of New Mexico.

Miller, W. R. \& Rollnick, S. (1991). Entrevista motivacional: preparando as pessoas para a mudança de comportamentos aditivos. Porto Alegre: Artes Médicas.

Myers, M. G. \& Brown, S. A. (1996). The Adolescent Relapse Coping Questionnaire: psychometric validation. Journal of Studies on Alcohol, 57, 40-46.

Oliveira, M., Jaeger, A. \& Schreiner, S. (2003). Abordagem Terapêutica no Tratamento da Dependência Química. Em R. M. Caminha, W. Ricardo, M. Oliveira \& N. M. Piccoloto (Orgs.), Psicoterapias Cognitivo-Comportamentais: Teoria e Prática (pp. 193-209). São Paulo: Editora Casa do Psicólogo.

Pechansky, F. (1999). Card games for drug users at risk for HIV transmission: a complementary approach to developing motivation and coping skills. Trabalho apresentado em Reunião Anual (Annual Meeting) da 23rd AMERSA National Conference, Alexandria.

Prochaska, J. O., DiClemente, C. C. \& Norcross, J. C. (1992). In search of how people change. Applications to addictive behaviors. American Psychologist, 47, 1102-1114.

Prochaska, J. O., Velicer, W. F., Fava, J. L., Rossi, J. S. \& Tsoh, J. Y. (2001). Evaluating a population-based recruitment approach and a stage-based expert system intervention for smoking cessation. Addictive Behaviour., 26, 583-602.
Schall, V., Monteiro S., Rebello, S. \& Torres M. (1999). Evaluation of the ZIG-ZAIDS game: an entertaining educational toll for HIV/AIDS prevention. Cadernos de Saúde Pública, 15, 107119.

Stark, M. J., Tesselaar, H. M., O'Connell, A. A., Person, B., Galavotti, C., Cohen, A. \& Walls, C. (1998). Psychosocial factors associated with the stages of change for condom use among women at risk for HIV and STDs: implications for intervention development. Journal of Consulting and Clinical Psychology, 66, 967-978.

Velicer, W. F., DiClemente, C. C., Prochaska, J. O. \& Brandenburg, N. (1985). Decisional balance measure for assessing and predicting smoking status. Journal of Personality and Social Psychology, 48, 1279-1289.

Williams, A. V. \& Pechansky, F. (2004a). O Joga da Escolha: Uma técnica psico-educacional para habilidades de enfrentamento de situações de risco em adolescentes usuários de drogas. Trabalho apresentado em Reunião Anual (Annual Meeting) da XXII Jornada Sul Rio-grandese de Psiquiatria Dinâmica, Porto Alegre.

Williams, A. V. \& Pechansky, F. (2004b). O Joga da Escolha: Uma técnica psico-educacional para habilidades de enfrentamento de situações de risco em adolescentes usuários de drogas. Trabalho apresentado em Reunião Anual (Annual Meeting) do XI Congresso da Associação Brasileira de Estudos de Álcool e Outras Drogas, São Paulo.

Williams, A. V. \& Pechansky, F. (2004c). The Choice Game: a psico-educational technique for cooping with risk situations in adolescents drug users. Trabalho apresentado em Reunião Anual (Annual Meeting) da NIDA International Forum, San Juan, Porto Rico.

World Health Organization (2002). The World Health Report: reducing risks, promoting healthy life. Genebra:World Health Organization. 


\section{TH WORLD FAMILY THERAPY CONGRESS}

Transformation and Globalization: Family Therapy in the 21 st Century International Family Therapy Associationc3

\section{Data:}

26 a 29 de Março de 2008

Local:

Porto, Portugal

Informações:

http://www.paragon-conventions.com/ifta2008/mailing/ifta08_01.html 